\title{
A mobilidade internacional acadêmica: características dos percursos de pesquisadores brasileiros
}

MARIA LUIZA DE SANTANA LOMBAS"

\section{Resumo}

Este artigo aborda o tema da internacionalização acadêmica, discutindo o movimento seguido por estudantes, professores e pesquisadores em direção a instituições universitárias e de pesquisa no exterior, com excepcional competência técnica e infraestrutura de qualidade para a formação pós-graduada e treinamento em pesquisa. São analisados os resultados de um estudo efetuado sobre bolsistas brasileiros da Capes e CNPq, em Ciência da Computação, Física/Astronomia e Economia, para a realização de doutorado pleno, doutorado sanduíche e pós-doutorado nos Estados Unidos, França e Grã-Bretanha, entre 1996 e 2007. Ressaltam-se as evidências de que o Brasil não sofre substantivas perdas de talentos científicos para o exterior, uma vez que o movimento predominante é de circulação, com o retorno ao país após a consecução das atividades propostas. A despeito de os destinos serem ambientes que favorecem o contato com formas diversas de produção do conhecimento, além de propiciarem a familiaridade com outros aspectos relacionados à prática de pesquisa, o local de atuação no Brasil, após o regresso, praticamente não difere em relação ao padrão nacional, compreendendo-se o das instituições propriamente acadêmicas.

Palavras-chave: Internacionalização. Mobilidade acadêmica. Brain circulation. Pesquisadores brasileiros.

* Universidade de Brasília, Brasil 
Sociologias, Porto Alegre, ano 19, no 44, jan/abr 2017, p. 308-333

\section{The international academic mobility: characteristics of Brazilian researchers' paths}

\section{Abstract}

This article discusses the issue of academic internationalization, by analyzing the mobility of students, professors and researchers toward the universities and research centers abroad, where exceptional technical competence and high quality infrastructure are found for obtaining post-graduate education and research training. It analyses the results of a study carried out involving Brazilian grantees from Capes and CNPq in the areas of Computer Science, Physics/Astronomy and Economics, who conducted full doctorate, sandwich doctorate and post-doctorate in the United States, France and Britain, between 1996 and 2007. Findings suggest that Brazil does not suffer substantial brain drain, since the predominant movement is related to circulation, with the return to the country after the end of the proposed activities abroad. Although the destinations consist of environments that foster the contact with various forms of knowledge production, also providing familiarity with other aspects related to the research practice, following the return to Brazil, the place of research activities practically does not differ with respect to the national pattern, being basically the academic institutions.

Keywords: Internationalization. Academic mobility. Brain circulation. Brazilian researchers. 


\section{Introdução}

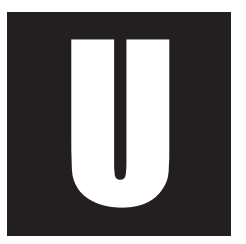

ma das notáveis manifestações de mudanças ocorridas na era da globalização econômica e da sociedade do conhecimento é, sem dúvida alguma, o incremento da mobilidade internacional acadêmica. Cada vez mais, as saídas para o exterior são recorrentes para estudantes, professores e pesquisadores de instituições universitárias e de pesquisa, assumindo durações e propósitos variados. Os deslocamentos passam a contemplar tanto estadas nos países de destino relativamente curtas, para visitas acadêmicas, participação em eventos científicos, etc. como estadas de longo termo, relacionadas aos estudos superiores e ao treinamento em pesquisa, entre outros. Geralmente, esses movimentos visam ambientes de alta intensidade de conhecimento, que favoreçam a atualização e incorporação de saberes, que estimulem a produtividade, a troca de ideias, as parcerias científicas e, também, que viabilizem a abertura de novas perspectivas de aproximação científica do estrangeiro.

No Brasil, o interesse de estreitar as relações científicas e tecnológicas com o ambiente internacional tem merecido crescente atenção por parte do governo federal, e vem motivando a adoção de diversos instrumentos de política, assim como o aporte expressivo de recursos públicos, tendo como principal meta o estímulo às saídas de brasileiros para estudos pós-graduados e para pesquisas fora do país. Entre esses instrumentos, destacam-se os programas de bolsas de estudos no exterior geridos pela Capes e CNPq, que visam à formação doutoral, plena e parcial, e ao pós-doutorado, sobretudo, em países desenvolvidos.

Não obstante a preocupação das autoridades governamentais em procurar alinhar o país à nova dinâmica mundial, na busca por aumentar as suas potencialidades na produção de conhecimento, intensificando esforços pela via da internacionalização, pouco ainda se sabe sobre os 
efeitos resultantes das políticas adotadas nesse sentido. Por outro lado, ainda é modesta a literatura científica nacional que se dedica ao tema da internacionalização do ensino superior e da pesquisa e, mais especificamente, à mobilidade internacional acadêmica, com o foco para a realidade brasileira.

O presente trabalho analisa o movimento seguido por pesquisadores brasileiros para formação doutoral e pós-doutorado no exterior e sua atuação em pesquisa após o retorno ao país. São analisados aspectos relativos à predominância de gênero na realização dos percursos, ao momento de inserção internacional, aos destinos no exterior e ao ambiente profissional no Brasil, posterior ao regresso. As informações aqui tratadas são originárias de um estudo que abordou os efeitos das trajetórias de formação pós-graduada e realização de pesquisa no exterior sobre a internacionalização da produção do conhecimento (Lombas, 2013). Foram coletadas informações sobre ex-bolsistas da Capes e do CNPq que responderam ao questionário aplicado, os quais atuam em pesquisa em uma das seguintes áreas: Ciência da Computação, Física/Astronomia e Economia, e obtiveram bolsa de estudos nas modalidades de doutorado pleno, doutorado sanduíche e pós-doutorado nos Estados Unidos, França e Grã-Bretanha, no período entre 1996 e 2007.

O texto é organizado em quatro seções. Além da introdução, faz-se um caminho pela literatura, procurando demonstrar a expansão e as características da mobilidade acadêmica na atualidade. Em seguida, discutem-se peculiaridades da população de pesquisadores brasileiros em apreço, considerando os aspectos tomados para análise. Por fim, são feitas as considerações finais. 


\section{O fluxo internacional acadêmico}

Cruzar fronteiras geográficas na busca por enriquecimento intelectual e por prestígio, inerentes à boa formação educacional não é recente, sendo registrada a sua ocorrência em vários momentos da história (Ben-David, 1974; Charle; Verger, 1996; Le Goff, 2006). No mundo contemporâneo, no entanto, são os acadêmicos que, de uma maneira geral, mais se deslocam de seus países com esse intento, sobretudo, para centros internacionalmente reconhecidos pelo alto padrão de excelência em ensino e pesquisa (Altbach, 1998). E, nas últimas décadas, esse fenômeno vem alcançando abrangência inusitada, agregando novos propósitos e adquirindo uma maior importância para a aquisição, transmissão, produção e transferência de conhecimentos.

Uma possível explicação para isso apoia-se nas transformações pelas quais tem passado a sociedade hodierna, especialmente em razão do processo de globalização, que trouxe evidências da forte dependência que a economia passou a ter do conhecimento (Castells, 2000; Gibbons et al.,1994; Guruz, 2008; Reich, 1994; Shwartzman, 2002). Porém, a globalização não apenas trouxe um novo significado para as relações econômicas mundiais, como alterou a dinâmica de outras esferas da sociedade. A lógica dos mercados globais, compreendida pelo intenso fluxo internacional e por noções como de competitividade, integração e colaboração, passou a fazer parte, mais intensamente, do modus operandi dessas outras esferas. A educação superior e a ciência são casos exemplares a esse respeito, tendo em vista as transformações que se fizeram sentir em seu interior e que readequaram suas relações com o ambiente externo, inclusive impulsionando a mobilidade acadêmica.

Os relatórios da UNESCO (2009; 2006) e da OCDE (2014) apontam que, em 1980, os estudantes que deixaram os seus países de origem com o objetivo de obter educação terciária no exterior (que inclui cursos 
de graduação e de pós-graduação) já eram em torno de 30\% a mais que em 1975, e superavam um milhão. Em 2012, são computados quatro milhões e meio de estudantes que seguiram essa trajetória, o que corresponde ao aumento de quase 500\% sobre as ocorrências registradas em 1975. Com relação aos principais destinos, observa-se que Estados Unidos, Reino Unido, França, Alemanha, Canadá e Austrália continuam mantendo a liderança na lista de anfitriões, acolhendo mais do que 50\% do fluxo de estrangeiros. Porém, outras regiões do planeta também passam a sobressair nessa lista, como uma possível consequência do processo de internacionalização que abrange as universidades de um número cada vez maior de países.

No que se refere especificamente ao envolvimento de estudantes em formação pós-graduada fora de seus países, pode-se ter uma ideia da dimensão que vem alcançando esse tipo de mobilidade internacional mediante estudos da National Science Foundation (2011). Em 1980, um pouco mais de 50.000 desse contingente obteve visto temporário para realizar, com dedicação integral, mestrado e doutorado nos Estados Unidos, nos campos da ciência, engenharia e saúde. Já em 2008, registram-se aproximadamente 130.000 estudantes com visto temporário inscritos nesses cursos, enquanto nos mesmos campos do conhecimento e condições de migração são também contabilizados 29.212 pesquisadores estrangeiros realizando o pós-doutorado. Em outro trabalho da National Science Foundation (2010), verifica-se que no ano acadêmico de 20082009, cerca de 115.000 estrangeiros estavam inseridos exclusivamente em programas de doutorado, nos diversos campos do conhecimento oferecidos pelas instituições americanas (ciências, engenharias e os campos considerados como não ciências), embora o referido período ainda não tivesse acompanhado as maiores taxas de crescimento registradas nos anos acadêmicos que o antecederam nessa década. 
Contudo, o intenso fluxo internacional de estudantes e pesquisadores registrado na atualidade não chama atenção apenas em termos de sua magnitude, mas também pelas características que está assumindo. Conforme apontam os dados, os estudos no exterior estão, cada vez mais, fazendo parte das aspirações dos que pleiteiam a formação terciária. Isso não ocorre unicamente pelo aumento da demanda global por ensino superior, pois verifica-se que, para alguns países, a taxa de crescimento da mobilidade tem sido superior à taxa relativa ao envolvimento local de estudantes em ensino terciário (UNESCO, 2009). Além da falta de acesso a esse ensino no próprio país, a escolha por estudos no exterior é ainda pautada por critérios de qualidade, vis-à-vis, ao que se poderia dispor no local de origem. Essa escolha é, também, determinada pelo interesse de complementar a formação educacional obtida ou de buscar conhecimentos especializados em ambientes que teriam as melhores condições de oferecê-los (Wit, 2009), bem como, para incorporar conhecimentos sobre outras culturas, agregando à formação um traço cosmopolita (Lewin, 2009). Isso significa que o movimento vem atraindo não somente mais estudantes de nações cujos sistemas de ensino superior e científico ainda são incipientes, como de nações que estão ampliando suas capacidades internas e de outras que já se encontram plenamente desenvolvidas (Altbach, 1998; Lewin, 2009).

Em se tratando dos destinos, a literatura vem reportando que as escolhas estão sendo orientadas pela excelência da qualificação, priorizando centros produtores de conhecimento de ponta. Isso não significa que houve mudanças substantivas na geografia do fluxo, pois tais centros se concentram, geralmente, nos países avançados do Ocidente. Porém, eles também começam a surgir nos países emergentes, que passam a acolher uma parte crescente desse movimento (OECD, 2014). Em determinadas áreas, embora em menores proporções que os demais, os países me- 
nos desenvolvidos estão sendo, também, alvo de atração da mobilidade acadêmica, seja porque oferecem possibilidade de estudo, seja porque dispõem de excepcionais recursos naturais para pesquisa (Regets, 2007; UNESCO, 2009). As escolhas dos centros produtores de conhecimento são também sensíveis às afinidades de idioma, culturais, regionais, etc. e à especificidade dos estudos (Scott, 1998). Da mesma forma, influenciam a acessibilidade a informações sobre a oferta e a qualidade das instituições universitárias do estrangeiro ${ }^{1}$, a diversidade de opções existentes de ensino superior e o incentivo institucional oferecido, tanto no sentido de estimular as saídas como no de acolher estudantes de outros países (Altbach, 1998; Lewin, 2009; Scott, 1998).

Os deslocamentos de pesquisadores para fora de seus países não estão acontecendo somente uma única vez nas respectivas carreiras científicas, como decorrência dos estudos de graduação no exterior ou de um treinamento em pesquisa, mediante a realização do doutorado, ou propriamente do desenvolvimento de um único pós-doutorado. O movimento tem se caracterizado como um processo contínuo de inserção internacional, ocorrendo repetidas vezes, em momentos distintos da atuação profissional, com duração e destinos variados, onde é possível encontrar recursos cognitivos e materiais para a pesquisa e que propiciem o permanente entrosamento com o ambiente científico no exterior. Desse modo, os percursos tendem a assumir o sentido de circulação transnacional de pessoas altamente qualificadas, ou brain circulation, resultante de várias idas a e vindas do estrangeiro, que se orienta predominantemente para a vinculação a centros com maior intensidade de conhecimento, onde são estabelecidos os padrões e os paradigmas científicos que, dadas essas características, dispõem de condições satisfatórias para atrair o tra-

\footnotetext{
${ }^{1}$ Inclusive, contando com o acesso a rankings mundiais sobre o desempenho das instituições universitárias.
} 
balho científico e manter relações colaborativas de pesquisa com outros centros (Ackers, 2005; Jöns, 2007; Meyer et al., 2001). Isso sem contar com a maior frequência em congressos, seminários e outras atividades que implicam saídas de curtíssimo prazo.

Progressivamente, os estudos no exterior vêm se tornando um componente importante para a formação profissional, na medida em que contribuem no desenvolvimento de competências, qualidades, atitudes e experiências que propiciam a conquista de competitividade no mercado de trabalho² (Lewin, 2009; Sadlak, 1998). Além de proporcionar a aquisição da formação educacional almejada, a exposição internacional vem favorecendo as relações interculturais, as trocas de conhecimentos e o estabelecimento de contatos sociais e profissionais, os quais são requisitos que ganham relevância no mundo atual. Na atividade de pesquisa, a experiência advinda do treinamento ou a realização de pesquisa propriamente dita no exterior torna-se cada vez mais necessária. Igualmente à aquisição de conhecimentos e à atualização sobre descobertas e inovações, os deslocamentos têm estimulado a produtividade e oportunizado o acesso aos canais científicos de comunicação, os intercâmbios e as colaborações inerentes ao trabalho científico, e, ainda, a abertura de novas perspectivas de interação com o exterior.

Os efeitos do fluxo internacional estão, igualmente, transcendendo as expectativas individuais. A presença massiva de estudantes e pesquisadores estrangeiros passa a influenciar o ambiente das instituições receptoras, constituindo-se um importante recurso acadêmico de exper-

\footnotetext{
${ }^{2}$ Sadlak aponta um conjunto de vantagens que normalmente tem sido atribuído para os estudos no exterior, que são: "[...] acquiring new knowledge and competences; improving knowledge of a foreign languages; familiarization with new teaching methods as well as new scientific equipment, organization of laboratories, etc.; opportunities to purchase new books, software, etc.; establishing new personal contacts, professional networking, etc.; familiarization with another country, its institutions and their functions; personal development and building of self-confidence." (1998, p.105).
} 
tise técnica e de perspectiva transcultural (Altbach, 1998). Na atividade de pesquisa, essas instituições ainda se beneficiam com a absorção de conhecimentos provindos de outros lugares, com as trocas e a geração de novos saberes, muito dos quais não são difundidos por outros meios (Laudel, 2003). Por outro lado, o estudo e a pesquisa no exterior são importantes elementos de transferência de conhecimentos para os locais de origem. Os egressos trazem consigo e disseminam em seu cotidiano acadêmico ou profissional as informações, práticas, hábitos, valores que foram adquiridos, e viabilizam as relações entre seus respectivos países e aqueles que os acolheram em sua trajetória internacional (Altbach, 1998).

Esses e outros efeitos benéficos resultantes da mobilidade acadêmica têm estimulado iniciativas institucionais, nacionais e até mesmo regionais, em várias partes do planeta, voltadas à promoção de programas estratégicos para atração de estudantes, professores e pesquisadores estrangeiros, ao mesmo tempo em que são envidados esforços para o envio dos nacionais para o exterior. Não restam dúvidas de que a China e a Índia são exemplares no envio de seus universitários para países desenvolvidos do ocidente. Mas, de modo contínuo, a União Europeia, dentro da política de integração regional implementada, vem também mantendo programas de incentivo à mobilidade acadêmica dentro dos países membros (Wit, 2009). Em 2011, o governo dos Estados Unidos lançou o programa 100,000 Strong in the Americas, visando aumentar o intercâmbio estudantil no continente americano. Com essa iniciativa, até 2020, os EUA esperam receber até 100.000 estudantes de outros países das américas e enviar o mesmo número de estadunidenses para esses países (Departamento de Estado dos Estados Unidos, 2011).

Naquele mesmo ano, o governo brasileiro lançou o Programa Ciência sem Fronteiras (CsF), com metas bastante ambiciosas, se comparadas aos programas tradicionais de bolsas de estudos no exterior, consideran- 
do-se o escopo e dimensão do atendimento. Busca-se contribuir para a internacionalização da produção do conhecimento nacional em duas direções: no sentido de aumentar vigorosamente o fluxo internacional de estudantes e pesquisadores brasileiros provenientes da academia, assim como oferecer oportunidades para que estudantes que integram o sistema de formação tecnológica e profissionais que atuam no desenvolvimento tecnológico do setor produtivo realizem trajetórias de treinamento fora do país; e, no sentido de estimular a internacionalização do ambiente acadêmico nacional com a vinda de jovens cientistas, entre os quais, brasileiros que emigraram, e pesquisadores renomados do exterior (Brasil, 2011).

\section{Os percursos seguidos por pesquisadores brasileiros}

As principais agências nacionais de fomento à pós-graduação e à pesquisa - Capes e CNPq - têm sinalizado que a grande maioria dos seus bolsistas retorna ao país após a consecução das atividades propostas no exterior, baseando-se nas informações constantes em seus registros sobre a comprovação de usufruto do bilhete aéreo de regresso. Tais informações não divergem de estudos empíricos realizados, que trazem evidências de que apenas uma minoria permanece em outro país (De Meis; Longo, 1990; Lombas, 1999; 2013; Meneghini, 1991; Schwartzman, 1978) e que as taxas de não retorno não chegam a ser significativas, considerando-se a capacidade de formação de novos pesquisadores pelo sistema nacional de pós-graduação (Guimarães, 2002). No estudo tomado como referência neste artigo, a proporção dos sujeitos que optaram por ficar no exterior não ultrapassou 5\%, sendo insignificantes as diferenças em relação à área do conhecimento de atuação em pesquisa, conforme é apresentado na Tabela 1.

Os resultados obtidos também não destoam de outros trabalhos sobre mobilidade internacional, com diferentes universos de estudantes de 
pós-graduação e profissionais em pesquisa científica, considerando-se alguns outros traços característicos. Constata-se que o número de homens supera em muito o de mulheres, girando em torno de quatro vezes mais, nas três áreas analisadas. Converge, portanto, com o que tem sido realçado pela literatura especializada, de que o gênero é um importante fator interveniente na propensão à mobilidade e que não pode ser negligenciado nos estudos efetuados em relação a carreira acadêmica (Ackers, 2004; Fernandez-Zubieta et al., 2013). Nesta, a aderência feminina aos deslocamentos para outro país tende a ser bem menor que a masculina, com vistas à realização da etapa mais avançada da formação em pesquisa - o doutorado - e no pós-doutorado, sobretudo, em razão das obrigações familiares já assumidas (Ackers, 2004). 
Tabela 1. Características da população e dos percursos por área do conhecimento

\begin{tabular}{|c|c|c|c|c|}
\hline & \multirow{2}{*}{ Características } & \multicolumn{3}{|c|}{ Áreas do Conhecimento } \\
\hline & & $\begin{array}{c}\text { Ciência da } \\
\text { Computação }\end{array}$ & Física & Economia \\
\hline \multirow{2}{*}{$\begin{array}{l}\text { Pesquisadores que } \\
\text { residem no Brasil }\end{array}$} & $\mathbf{N}^{\circ}$ de pesquis adores & 131,0 & 174,0 & 99,0 \\
\hline & $\%$ do total & 94,9 & 96,7 & 95,2 \\
\hline Gênero & |Homens & 77,1 & 79,3 & 80,8 \\
\hline \multirow{5}{*}{$\begin{array}{c}\text { Trajetórias de } \\
\text { formação doutoral e } \\
\text { de realizacãa de } \\
\text { pesquisa no exterior }\end{array}$} & Doutorado sanduíche (DS) & 28,2 & 16,7 & 30,3 \\
\hline & Doutorado pleno (DP) & 44,3 & 10,3 & 50,5 \\
\hline & Pós-doutorado (PD) & 3,8 & 46,0 & 4,0 \\
\hline & DS + PD & 9,9 & 16,1 & 3,0 \\
\hline & $\mathbf{D P}+\mathbf{P D}$ & 13,7 & 10,9 & 12,1 \\
\hline \multirow{4}{*}{$\begin{array}{c}\text { Destinos das } \\
\text { trajetórias (países) }\end{array}$} & Estados Unidos & 39,7 & 63,8 & 55,6 \\
\hline & França & 34,4 & 34,5 & 20,2 \\
\hline & Grã_Bretanha & 33,6 & 15,5 & 39,4 \\
\hline & Outros(AL, IT,SU, CA, ES, HO, JÁ,BE, AU, SE, etc.) & 9,2 & 30,5 & 8,1 \\
\hline \multirow{4}{*}{$\begin{array}{l}\text { Ambiente de } \\
\text { realização das } \\
\text { trajetórias no } \\
\quad \text { exterior }\end{array}$} & Centro Universitário & 78,6 & 71,8 & 92,9 \\
\hline & Instituto de pesquis a & 9,2 & 23,6 & 7,1 \\
\hline & Laboratório & 26,0 & 29,3 & 2,0 \\
\hline & Centro de P\&D & 26,0 & 29,3 & 2,0 \\
\hline \multirow{7}{*}{$\begin{array}{c}\text { Local onde } \\
\text { desenvolve pesquis a } \\
\text { no Brasil }\end{array}$} & Universidade & 92,4 & 90,2 & 84,8 \\
\hline & Instituição de pesquisa & 4,6 & 12,6 & 11,1 \\
\hline & Empresa & 5,3 & 1,1 & 0,0 \\
\hline & Orgão Público & $\mathbf{0 , 0}$ & 1,1 & 6,1 \\
\hline & Instituto tecnológico & 2,3 & 0,6 & 0,0 \\
\hline & ONG & 0,8 & 0,0 & 2,0 \\
\hline & Organismo internacional & 0 & 0 & 1 \\
\hline
\end{tabular}

Fonte: Lombas (2013)

Há que se considerar, ainda, que outros fatores podem intervir nas áreas analisadas, favorecendo proporções assimétricas entre homens e mulheres, com a preponderância dos primeiros. Isso porque é plausível admitir para cada gênero diferentes motivações operando na escolha pro- 
fissional, assim como, no que respeita aos domínios do saber, padrões socioculturais distintos afetando as suas respectivas aspirações (Canêdo, 2004; Correll, 2004). Nesse sentido, mesmo na área de Economia, é razoável supor que a desigualdade sob esse aspecto seja tão expressiva como a observada na Tabela 1, tendo como explicação o crescente uso de ferramentas da Matemática, cujo domínio fora preferencialmente atribuído aos homens (Albert, 2003).

No que se refere aos momentos da atividade científica em que ocorrem as saídas para o exterior, verifica-se que a formação doutoral e o pós-doutorado costumam ser fortes motivações, sendo, inclusive, apontadas como o ponto de partida para futuros afastamentos do país de origem (Laudel, 2005). Decerto que, além da expectativa de aprendizado, esses momentos de inserção internacional são propícios à convivência com a cultura estrangeira, com o ambiente institucional de pesquisa do país de destino e frutíferos para o estabelecimento de interações científicas duradouras, podendo proporcionar as trocas e transferências de conhecimento, mesmo depois da volta ao local de origem.

Algumas peculiaridades, no entanto, são encontradas no universo de estudo, que acompanham as especificidades da área de atuação e do contexto da pós-graduação no Brasil. Para os cientistas da computação e os economistas, a inserção internacional em pesquisa se deu, sobretudo, mediante a realização do doutorado no exterior, o que é geralmente verificado como a trajetória mais comum seguida nas respectivas áreas. Embora a grande maioria tenha buscado uma formação doutoral plena, é bastante expressivo o número daqueles que fizeram apenas parte dos seus estudos no estrangeiro. O que denota a interveniência da política de bolsas adotada pelas agências federais de fomento a partir dos anos 90, no sentido de privilegiar a modalidade de doutorado sanduíche, tendo em vista a expansão e progressiva consolidação de programas de pós- 
-graduação no país ${ }^{3}$. Já os físicos exibem traços mais próximos ao padrão assumido nos campos do conhecimento de maior tradição no país, no que se refere às saídas para pesquisas no exterior terem início, principalmente, após a obtenção do título de doutorado, com o propósito de realizar o pós-doutorado ${ }^{4}$. Com esse percurso, registram-se $46 \%$ dos sujeitos que responderam ao questionário aplicado.

As informações coletadas revelam que o movimento em direção ao exterior não se dá apenas uma única vez para boa parte dos pesquisadores analisados. Além de $23 \%$ dos respondentes terem combinado trajetórias de formação doutoral e, em outro momento, o pós-doutorado em instituições estrangeiras, observa-se que a atividade de pesquisa motivou outras saídas do país. No estudo aqui citado, verificou-se que, cerca de $10 \%$ dos respondentes realizaram mais de um pós-doutorado fora, indicando que este percurso não somente assumiu o caráter de treinamento ou aperfeiçoamento em pesquisa, mas também de reciclagem e arejamento científico. O estreitamento de relações acadêmicas e de pesquisa com o ambiente internacional foi igualmente observado, sendo este por curtos espaços de tempo, compreendendo dias ou semanas, e ocorrendo na condição de visiting scholar e de visiting researcher.

As informações também trazem indicativos de que as trajetórias que abrangem a formação doutoral e o pós-doutoramento no exterior não foram realizadas, necessariamente, de modo consecutivo. Pode-se, inclusive, supor que houve um intervalo relativamente longo, compreendendo a permanência no Brasil antes de uma nova estada no exterior para o pós-doutorado. Decerto que as obrigações institucionais, mediante o

\footnotetext{
${ }^{3}$ Conforme tem sido abordado por Velho (2001), Velloso (2002), Balbachevsky (2005), Sobral (2008), Schwartzman (2009), Lombas (2011).

${ }^{4}$ Ver, por exemplo, os estudos que são discutidos por Meneghini (1995) e que, nos anos 90, causaram impacto sobre os debates em torno da política de concessão de bolsas de estudos no exterior.
} 
termo de compromisso firmado com as agências de fomento que concederam a bolsa de estudo e o próprio vínculo empregatício mantido no país podem pesar na decisão de retorno imediato e aqui permanecer por algum tempo. Mas, não deixa de chamar atenção a pequena proporção de jovens doutores, com dez anos ou menos de titulados, que combinou a formação doutoral e o pós-doutoramento no estrangeiro nesse intervalo de tempo, comparativamente àqueles que haviam obtidos seus títulos de doutorado há mais tempo (14\% dos jovens doutores contra 30\% dos seniores do total do conjunto).

Esses dados igualmente reforçam a suposição de que a realização do pós-doutorado no exterior teve tanto o propósito de treinamento e aperfeiçoamento em pesquisa, normalmente realizado pelos recém-doutores, como de reciclagem e arejamento científico, peculiar aos que estão em estágio mais avançado da profissão científica. Eles ainda sugerem que o movimento para fora do país tem a perspectiva de acompanhar todo o percurso profissional realizado pelo pesquisador, o que corrobora o sentido de circulação que se procura abordar no presente estudo.

As trajetórias que não foram contempladas com apoio da Capes e $\mathrm{CNPq}$ não variam substancialmente em relação à orientação que as inserções internacionais tomaram, motivadas pela concessão de bolsa de estudos, sendo que, na maioria dos casos, o destino visado foi, pelo menos, um dos três países eleitos na delimitação do universo de estudo. De fato, esses países são referência mundial na produção do conhecimento de ponta, em diversas especialidades, como decorrência do elevado nível de excelência que possuem seus sistemas nacionais de ensino superior e de C, T \& I, e da forte interação que esses sistemas mantêm entre si. Por conseguinte, são os maiores acolhedores de estudantes, professores e pesquisadores provenientes de outros países (Guruz; 2008). Os demais destinos compreendem, majoritariamente, países também considerados 
cientificamente centrais e que costumam acolher, igualmente, proporções significativas do fluxo (Alemanha, Suíça, Bélgica, Canadá, Holanda, Itália, Japão, Austrália). Além desses, o trajeto dos respondentes em direção ao exterior abrangeu outros países na Europa (Espanha, Portugal, Suécia, Irlanda, Rússia, Noruega, Luxemburgo, Áustria, Hungria), muitos dos quais fazem parte da rota da mobilidade, e, também, o Chile.

No entanto, a incidência de estadas em um ou outro país é variável conforme a área de atuação dos respondentes. Entre os economistas, foi expressivamente maior o fluxo para os Estados Unidos e Grã-Bretanha do que para a França e outros países. Isso pode ser explicado pelo fato de que nos dois primeiros se situam instituições universitárias mundialmente reconhecidas por produzirem conhecimento no mainstream da área. Também entre os físicos, considerando-se a mesma racionalidade de ordem cognitiva, os percursos ocorreram mais frequentemente para os Estados Unidos. Mas a França é que assume o segundo destino mais frequentado por esses sujeitos, possivelmente devido à maior importância das instituições francesas ou situadas naquele país para o desenvolvimento de certos campos da Física, quando comparadas com as da Grã-Bretanha. Foi nesta área, também, que houve a maior incidência de movimentação para outros locais, o que vem reforçar o forte caráter internacional de seus campos. Já entre os cientistas da computação, os três países que integram a presente pesquisa prevaleceram na indicação como destino assumido sobre os demais. Porém, entre esses, percebe-se uma leve preponderância de estadas nos Estados Unidos, a qual pode ser motivada pela superioridade das instituições americanas na produção do conhecimento relativo à área ${ }^{5}$.

As estadas em países considerados cientificamente centrais para a formação doutoral e para o pós-doutorado deram-se, sobretudo, em cen-

\footnotetext{
${ }^{5} \mathrm{Ma}$, Ni e Qiu, por exemplo, mostram que entre as 23 universidades classificadas como as $10 \%$ melhores do mundo, em termos de produção, desenvolvimento, inovação e prestígio em pesquisa na área da Ciência da Computação, 17 são americanas (2008).
} 
tros universitários, ou seja, em espaços que se dedicam propriamente à transmissão do conhecimento e, quando feita nesses ambientes, a pesquisa está, via de regra, associada à formação. Porém, a presença nesses locais variou de acordo com as áreas de atuação. A grande maioria dos economistas concentrou suas atividades nesses centros e pouquíssimos procuraram também realizá-las em outros espaços de produção do conhecimento, mesmo dentro das universidades que frequentaram. As ocorrências registradas entre esses sujeitos, no que diz respeito às estadas em instituto de pesquisa, laboratório e centro de pesquisa e desenvolvimento alcançaram, no total, $11 \%$. Uma possível justificativa para isso é a própria natureza do conhecimento que a área produz, e que pode ser desenvolvido, de modo pleno, nas dependências dos centros universitários.

Na Ciência da Computação e na Física, as trajetórias foram muito mais diversificadas em termos do contexto de sua realização, sendo constatada também uma significativa presença dos sujeitos dessas áreas em institutos de pesquisa, laboratórios e centros de pesquisa e desenvolvimento. Essas evidências indicam que os percursos de formação doutoral e de pesquisa, nos países onde esses pesquisadores estiveram, propiciaram a frequência em ambientes que normalmente conferem a oportunidade de lidar com outros modos de desenvolvimento da pesquisa, mediante a experimentação e a aplicação dos conhecimentos. Ademais, muitos desses ambientes costumam também conjugar o conteúdo científico com outros saberes (por exemplo, gestão da pesquisa, interação com diferentes atores sociais, etc.), que aumentariam a importância das trajetórias realizadas para a carreira do pesquisador (Balbachevsky; Do Couto e Silva, 2011; Velho, 2001).

Entretanto, o local de atuação em pesquisa após o regresso ao Brasil é predominantemente a universidade. Nota-se que apenas uma pequena proporção (15\%) informou atuar em pesquisa em outro tipo de institui- 
ção. Na Física e na Economia, as instituições diretamente voltadas para o desenvolvimento de pesquisa foram apontadas por pouco mais de $10 \%$ dos respondentes. Em órgão público, a maior proporção de resposta é da Economia e corresponde a $6 \%$. Na Ciência da Computação, a atuação em empresas foi indicada por apenas $5 \%$ dos sujeitos. Os demais locais sugeridos mereceram somente $2 \%$ do total das respostas. Tal informação indica que a experiência advinda da inserção científica em países onde se verificam espaços variados de produção do conhecimento, em que alguns informaram ter estado, não logrou fazer com que a atuação desses em pesquisa no país fosse um pouco mais diversificada.

Estudos anteriores sobre doutores brasileiros já haviam apontado que, no país, as instituições universitárias seriam o destino certo para o desenvolvimento de pesquisas. Do ponto de vista das aspirações profissionais, um estudo realizado com bolsistas da Capes, inseridos em programa de doutorado no exterior, mostrou que a principal motivação para o retorno ao país seria a expectativa de melhores oportunidades no trabalho profissional futuro e este estaria relacionado à atividade de ensino e de pesquisa em instituição de ensino superior nacional (Lombas, 1999). No universo de doutores formados no país, analisados por Velloso e Velho (apud Velloso, 2006), observa-se que a grande maioria realizava pesquisa em seu trabalho profissional e este era, majoritariamente, desenvolvido em universidade. O levantamento feito pelo CGEE, sobre doutores titulados no país, já referido neste trabalho, mostra, igualmente, que em 2008 apenas 11,06\% dos formados entre 1996 e 2006 trabalhavam para a administração pública. Na atividade profissional de C\&T (o que sugere ser em instituições propriamente de pesquisa) a proporção não chegava a $4 \%$ e, na indústria de transformação era um pouco mais de 1\%. O mesmo levantamento mostra, ainda, que em outras 10 categorias de atividade não se somavam $8 \%$, enquanto a grande maioria (isto é, $77 \%$ ) concentrava-se 
na atividade de Educação (CGEE, 2010, p. 220). Esses resultados sugerem que, muito mais vigorosamente do que a experiência advinda da formação doutoral e da realização de pós-doutorado em países cientificamente mais avançados, outros fatores estariam interferindo no comportamento dos nossos respondentes, no que diz respeito ao local que utilizam para o desenvolvimento de pesquisa no Brasil.

\section{Considerações finais}

No presente trabalho, procurou-se realçar a importância que tem merecido o movimento internacional acadêmico na atualidade, não apenas devido à grandeza de suas dimensões, mas, sobretudo, pelos seus propósitos. Buscou-se mostrar, também, que o fluxo não tem sido impulsionado, somente, por motivações individuais, mas, igualmente, por interesses institucionais, nacionais e, mesmo, internacionais. $\mathrm{O}$ papel chave que as relações internacionais assumiram na economia globalizada, as quais surtem efeitos sobre o ensino superior, o desenvolvimento científico, tecnológico e de inovações, tem levado as nações a intensificarem os estímulos para inserção de seus pesquisadores em ambientes produtores de conhecimento de ponta, na expectativa de que tanto seja possível a aquisição de competência tácita e codificada como seja factível a participação nacional em redes globais de pesquisa.

Os resultados que foram tomados para análise neste trabalho corroboram as evidências de que o Brasil não sofre perdas significativas dos seus talentos. Semelhantemente ao verificado em outros estudos realizados com brasileiros, a grande maioria regressou após a realização de suas trajetórias de formação doutoral e de pós-doutorado no exterior e permanece no país, desenvolvendo atividade de pesquisa. O ponto de partida para as inserções internacionais, isto é, se para formação doutoral, plena 
ou parcial, ou se para o pós-doutorado, variou entre os sujeitos e parece refletir a conduta das respectivas áreas no Brasil, bem como, as estratégias de indução da política de bolsas de estudos adotadas pela Capes e pelo CNPq, especialmente, nos anos 90.

$\mathrm{O}$ afastamento com fins de estudos e pesquisas fora do país não ocorreu, apenas, uma única vez na carreira científica para parte expressiva dos sujeitos, abrangendo outras estadas no estrangeiro, para a realização de um ou mais pós-doutorados, assim como, alguns períodos de curta duração, na condição de visiting scholar ou visiting researcher. Igualmente ao que ocorreu nos trajetos contemplados com bolsa do governo brasileiro, esses movimentos se deram, principalmente, em direção a países produtores de conhecimento de ponta, provedores de sistemas nacionais de ensino superior e de C, T, \& I com elevado padrão de excelência e de integração entre si. Pelas médias etárias verificadas, é possível supor-se, inclusive, que esses afastamentos do país tendem a se repetir para uma boa parte dos sujeitos, especialmente, para aqueles que podem ser considerados jovens doutores.

As informações ainda trazem indicativos de que os percursos que sucederam à primeira trajetória no exterior, para estudos ou pesquisas, não se deram de modo consecutivo, sendo possível admitir que tenha havido um intervalo relativamente longo, abarcando um período de atuação laboral no Brasil, antes de uma nova inserção internacional. Do mesmo modo, elas apontam que o pós-doutoramento não teve somente o propósito de complementar a formação doutoral, mediante o treinamento ou aperfeiçoamento em pesquisa, mas, também visando à reciclagem ou arejamento no trabalho científico. Ou seja, a conduta de sujeitos da pesquisa realizada estaria consoante com as tendências mundiais observadas na atividade científica, que buscam atribuir importante papel à mobilidade internacional, motivando as idas e vindas de pesquisadores do exte- 
rior, as quais se consubstanciam em circulação transnacional de pessoas altamente qualificadas ou brain circulation.

A despeito de os destinos serem os países considerados referência mundial em desenvolvimento científico, tecnológico e de inovações e de boa parte dos sujeitos terem a oportunidade de frequentar ambientes que, geralmente, favorecem o contato com formas diversas de produção do conhecimento, além de propiciarem a familiaridade com outros aspectos relacionados à atividade científica, o local de atuação em pesquisa no Brasil, após o regresso, praticamente, não variou, compreendendo-se nas instituições propriamente universitárias. Somente 16\% dos sujeitos informaram atuar em outro local. Considerando-se que o modo de condução das pesquisas na maioria das universidades brasileiras em pouco se diversifica e tende a contemplar as interações com outros ambientes de produção do conhecimento ainda de forma restrita, fica a dúvida de se as experiências obtidas com as trajetórias realizadas no exterior estejam sendo amplamente aproveitadas nesse aspecto, especificamente. Porém, caberiam futuros estudos com o propósito de entender como se dá o aproveitamento dos egressos do exterior na atividade de pesquisa no Brasil.

Maria Luiza de Santana Lombas é analista sênior em Ciência e Tecnologia da CAPES - Coordenação de Aperfeiçoamento de Pessoal de Nível Superior, Brasil. 々malu.lombas@terra.com.br 
Sociologias, Porto Alegre, ano 19, no 44, jan/abr 2017, p. 308-333

\section{Referências}

1. ACKERS, L. Moving people and knowledge: scientific mobility in the European Union. International Migration, Oxford, UK, v. 43, n.5, pp. 100-127, 2005.

2. ACKERS, L. Managing Work and Family Life in Peripatetic Careers: The Experiences of Mobile Women Scientists in the European Union. Women's Studies International Forum, London, UK, v.27, n. 3, pp.189-201, 2004.

3. ALBERT, M. Universities and the Market economy: the differential impact on knowledge production in sociology and economics. Higher Education, Netherlands, v.45, pp. 147-182, 2003.

4. ALTBACH, P.G. Comparative Higher Education: knowledge, the university, and development. Connecticut: Ablex Publishing, 1998.

5. BALBACHEVSKY, E.; Do COUTO e SILVA, E. A diáspora científica brasileira: perspectiva para sua articulação em favor da ciência brasileira. Parcerias Estratégicas, Brasília, DF, v.16, n.33, pp. 163-176, jul. /dez. 2011.

6. BALBACHEVSKY, E. A pós-graduação no Brasil: novos desafios para uma política bem-sucedida. In: BROCK, C.; SCHWARTZMAN, S. (Ed.). Os desafios da educação no Brasil. Rio de Janeiro: Nova Fronteira, pp. 285-314, 2005.

7. BRASIL. Governo Federal. Ciência sem Fronteiras. 2011. Disponível em <http://www.cienciasemfronteiras.gov.br/web/csf>. Acesso em: 20 mai. 2015.

8. BEN-DAVID, J. O papel do cientista na sociedade: um estudo comparativo. Tradução de Dante Moreira Leite. São Paulo: Universidade de São Paulo, 1974.

9. CANÊDO, L.B. Masculino, feminino e estudos universitários no estrangeiro: os bolsistas brasileiros no exterior (1987-1998). In: ALMEIDA, M. et al. (Org.). Circulação internacional e formação intelectual das elites brasileiras. Campinas, SP: Editora da UniCamp, pp. 168-187, 2004.

10. CASTELLS, M. A sociedade em rede. Vol. 1. Tradução de Ronei de Venancio Majer. São Paulo: Paz e Terra, 2000.

11. CGEE - Centro de Gestão e Estudos Estratégicos. Doutores 2010: Estudos da demografia da base técnico-científica brasileira. Brasília: CGEE, 2010.

12. CHARLE, C.; VERGER, J. História das Universidades. Tradução de Elcio Fernandes. São Paulo: Editora da UNESP, 1996..

13. CORRELL, S.J. Constraints into Preferences: Gender, Status, and Emerging Career Aspirations. American Sociological Review, v. 69, n.1, pp. 93-113, 2004. 
14. De MEIS, L.; LONGO, P.H. The training of Brazilian biochemists in Brazil and in developed countries: cost and benefits. Biochemical Education, [S.I.], v. 18, n. 4, pp. 182-188, 1990.

15. DEPARTAMENTO DE ESTADO DOS ESTADOS UNIDOS. 100,000 Strong in the Americas. 2011. Disponível em <http://www.100kstrongamericas.org/pt-br/ about>. Acesso em: 20 mai. 2015.

16. FERNANDEZ-ZUBIETA, A.; MARINELLS, E.; PERES, S.E. What drives researchers' careers? The role of international mobility, gender and family. Sociology and Technoscience, v. 3, n. 3, pp. 8-30, 2013.

17. GIBBONS, M. et al. The New Production of Knowledge: the dynamics of science and research in contemporary societies. Sweden: Sage Publications Ltd, 1994.

18. GUIMARÃES, R. A diáspora: um estudo exploratório sobre o deslocamento geográfico de pesquisadores brasileiros na década de 90. Dados, v. 45, n. 4, pp.705 - 750, 2002.

19. GURUZ, K. Higher Education and International student mobility in the global knowledge economy. Albany, NY: State University of New York, pp.1-20, 2008.

20. JÖNS, H. Transnational mobility and the spaces of knowledge production: a comparison of global patterns, motivations and collaborations in different academic fields. Social Geography, [S.I.], v. 2, pp. 97 - 114, 2007.

21. LAUDEL, G. Migration currents among the scientific elite. Minerva, Netherlands, v.43, pp.377-395, 2005.

22. LAUDEL, G. Studying the brain drain: Can bibliometric methods help? Scientometrics, Budapest, v. 57, n.2, pp.215-237, 2003.

23. LE GOFF, J. Os Intelectuais na Idade Média. Tradução de Marcos de Castro. Rio de Janeiro: José Olympio, 2006.

24. LEWIN, R. The quest for global citizenship through study abroad. In: LEWIN, $\mathrm{R}$. (Ed.). The handbook of practice and research in study abroad: high education and the quest for global citizenship. Introduction. New York: Routledge, 2009.

25. LOMBAS, M.L. de S. A mobilidade internacional de pós-graduandos e pesquisadores e a internacionalização da produção do conhecimento: efeitos de uma política pública no Brasil, 2013. Tese (Doutorado em Sociologia) - Universidade de Brasília, Programa de Pós-Graduação em Sociologia, Brasília, DF, 2013. 
26. LOMBAS, M.L. de S. A circulação internacional de pós-graduandos e pesquisadores: uma prática de internacionalização da produção do conhecimento? In: Anais, XI CONLAB, 2011, Salvador: Universidade Federal da Bahia, 2011. Disponível em: <<http://circulaçãointernacionaldeposgraduandosepesquisadores_Artigo_XILABCS.pdf $>$. Acesso em: 1 set. 2013.

27. LOMBAS, M.L. de S. Há indícios de brain drain no Brasil? Um estudo sobre doutorandos no exterior. 1999. Dissertação (Mestrado em Educação) - Universidade de Brasília, Programa de Pós-Graduação em Educação, Brasília, DF, 1999.

28. MA, R.; NI, C.; QIU, J. Scientific research competitiveness of world universities in Computer Science. Scientometrics, Budapest, v.76, n. 2, pp. 245-260, 2008.

29. MENEGHINI, R. Performance of Brazilian scientists and the pattern of scientific training: a comparison between physicists and chemists. Ciência e Cultura, São Paulo, v. 47, n. 1/2, pp. 45- 49, 1995.

30. MENEGHINI, R. Performance of Brazilian scientists with previous PhD Training in Brazil and in developed countries: the case of chemists. Ciência e Cultura, São Paulo, v. 43, n. 5, pp. 343 -346, 1991.

31. MEYER, J-B.; KAPLAN, D.; CHARUM, J. Scientific nomadism and the new geopolitics of knowledge. International Social Science Journal, v. 53, pp. 309321, 2001.

32. NATIONAL SCIENCE FOUNDATION (NSF). Doctorate Recipients from U.S. Universities: 2010. Arlington, VA: NSF 12305, dez, 2011

33. NATIONAL SCIENCE FOUNDATION (NSF). Foreign Science and Engineering students in the United States. Arlington, VA: NSF, 10-324, jul. 2010

34. OECD. Education at a Glance 2014: OECD indicators. Disponível em: <http://dx.doi.org/10.1787/eag-2014-en.pdf>. Acesso em: 20 maio de 2015.

35. REGETS, M. Research issues in the international migration of highly skilled workers: a perspective with data from the United States. Working Paper, National Science Foundation, Arlington, VA, SRS 07-203, Jun., 2007.

36. REICH, R.B. O trabalho das nações: preparando-nos para o capitalismo do século 21. Tradução de Claudiney Fullmann. São Paulo: Educator, 1994.

37. SADLAK, J. Globalization and concurrent challenges for Higher Education. In: SCOTT, P. (Ed.) The globalization of Higher Education. Buckingham: Open University Press, pp.100-107, 1998. 
38. SCHWARTZMAN, S. Nacionalismo vs. internacionalismo en las políticas de formación de recursos humanos de alto nivel. In: AUPETIT, S.D.; GERARD, E. (Ed.) Fuga de cerebros, movilidad académica y redes científicas: perspectivas latinoamericanas. México, DF: CINVESTAV, pp. 63-73, 2009.

39. SCHWARTZMAN, S. A pesquisa científica e o interesse público. Revista Brasileira de Inovação, Rio de Janeiro, v.1, n.2, pp. 361-395, jul./dez., 2002.

40. SCHWARTZMAN, S. Brain drain: pesquisa multinacional? In: NUNES, E. de O. (Org.). A aventura sociológica: objetividade, paixão, improviso e método na pesquisa social. Rio de Janeiro: Zahar Editores, pp. 67-85, 1978.

41. SCOTT, P. Massification, internationalization and globalization. In: SCOTT, P.(Ed.) The globalization of Higher Education. Buckingham: Open University press, pp.108-129, 1998

42. SOBRAL, F.A.F. A pesquisa e a formação de recursos humanos. Ciência e Cultura, São Paulo, v. 60, n. esp, 2008.

43. UNESCO - Institute for Statistics. Global Education Digest 2009: comparing education statistics across the world. Disponível em: < http://www.uis.unesco.org/ Library/Documents/ged09-en.pdf>. Acesso em: 10 jan. 2013.

44. UNESCO - Institute for Statistics. Global Education Digest 2006: comparing education statistics across the world. Disponível em: <http://www.uis.unesco.org/ Library/Documents/ged06-en.pdf>. Acesso em: 10 jan. 2013.

45. VELHO, L. Formação de doutores no país e no exterior: estratégias alternativas ou complementares? Dados, v.44, n.3, p.607-631, 2001.

46. VELLOSO, J. Pós-graduação: egresso, trabalho e formação no país e no exterior. In: STEINER, J.E.; MALNIC, G.(Orgs.) Ensino superior: conceito e dinâmica. São Paulo: USP, pp. 177-242, 2006.

47. VELLOSO, J. (Org.) Formação no país ou no exterior? Doutores da pósgraduação de excelência: um estudo na Bioquímica, Engenharia Elétrica, Física e Química no País. Brasília: UNESCO, 2002.

48. WIT, H. de. Global citizenship and study abroad: a European comparative perspective. In: LEWIN, R. (Ed.) The handbook of practice and research in study abroad: high education and the quest for global citizenship. New York: Routledge, pp. 212-229, 2009.

Recebido: 28.09.2015

Aceito: 16.03.2016 